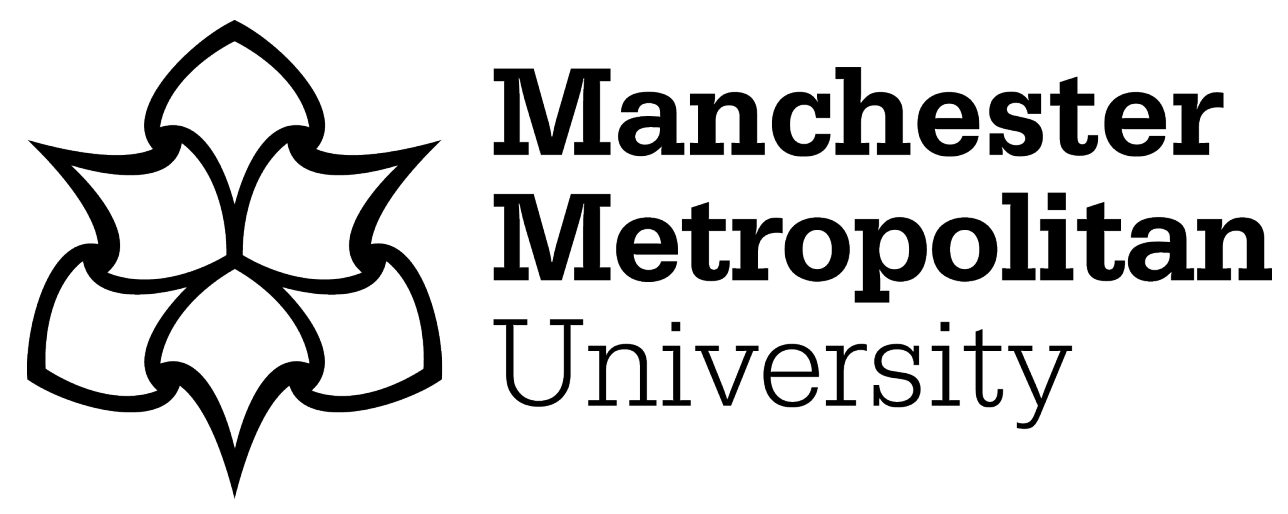

Massey, J ORCID logoORCID: https://orcid.org/0000-0002-4716-661X (2019) Gateways for consumption: a rhythmanalysis. Journal of Consumer Culture, 19 (3). pp. 417-437. ISSN 1469-5405

Downloaded from: https://e-space.mmu.ac.uk/623473/

Version: Accepted Version

Publisher: Sage

DOI: https://doi.org/10.1177/1469540519856403

Please cite the published version 


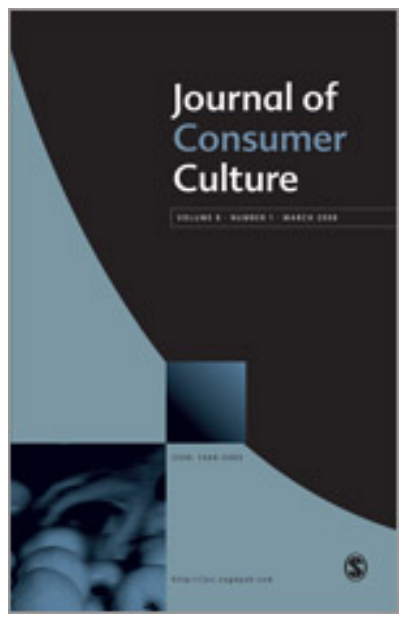

\section{Gateways for consumption: a rhythmanalysis}

\begin{tabular}{|c|c|}
\hline Journal: & Journal of Consumer Culture \\
\hline Manuscript ID & JOCC-18-0106.R3 \\
\hline Manuscript Type: & Original Article \\
\hline Keywords: & Manchester, Lefebvre, youth, urban space, consumption \\
\hline Abstract: & $\begin{array}{l}\text { This article uses participant observation data to explore teenagers' } \\
\text { presence in two urban public spaces in Manchester, England. The urban } \\
\text { spaces under investigation are public, but surrounded by retail outlets } \\
\text { and act as gateways for consumption. The aim is to answer the question } \\
\text { 'how do the rhythms of teenage life differ when ordinary and } \\
\text { extraordinary activities occur in urban public spaces of consumption?' } \\
\text { Lefebvre's Rhythmanalysis is employed to analyse the data and identify } \\
\text { instances of eurhythmia (harmonious rhythms), arrhythmia (discordant } \\
\text { rhythms) and polyrhythmia (multiple simultaneous rhythms) during } \\
\text { periods of typical and extraordinary use. Ordinarily the teenagers used } \\
\text { the spaces of consumption to mostly meet and socialise with friends with } \\
\text { a small number of them using the space to skateboard. This occurred } \\
\text { harmoniously alongside others who pass through these gateways to } \\
\text { consumption indicating multiple rhythms. The findings indicate the } \\
\text { teenagers were displaced from urban space during the staging of official } \\
\text { events which involved increased control from authorities such as the } \\
\text { local council and police. They were replaced by a different crowd of } \\
\text { people consisting of mostly families and adults. Paradoxically the } \\
\text { 'festival' atmosphere created by extraordinary events in the gateways of } \\
\text { consumption resulted more interaction amongst those present despite } \\
\text { increased control from the authorities. Rhythmanalysis proved useful in } \\
\text { understanding spaces of when researching spaces of consumption, as it } \\
\text { exposes the temporal and fluid nature of urban space. Ultimately, there } \\
\text { was no room for the presence of regular users (teenagers) during the } \\
\text { staging of extraordinary events indicating a lack of multiple rhythms. }\end{array}$ \\
\hline
\end{tabular}




\section{SCHOLARONE ${ }^{\text {m }}$ Manuscripts}




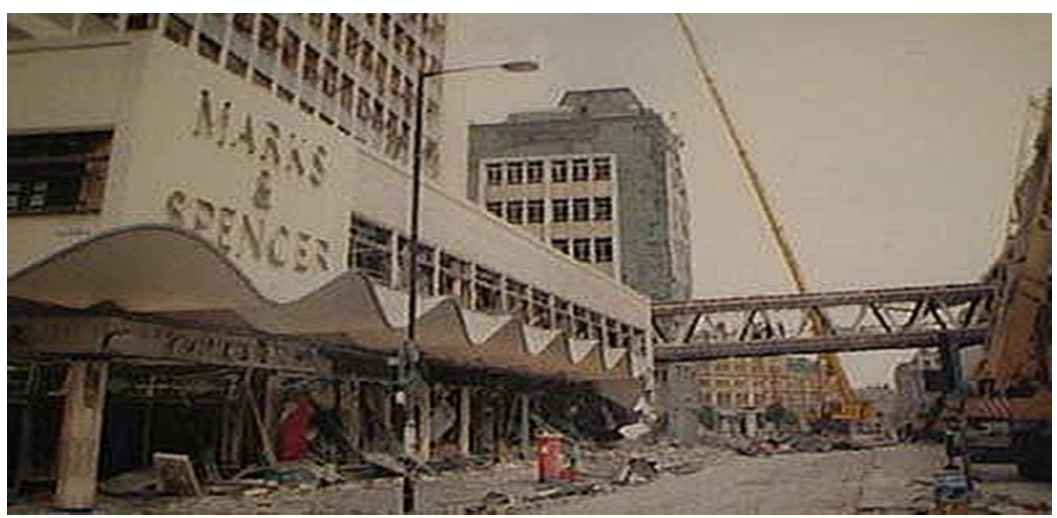

Image 1: Marks and Spencer post-bomb in 1996

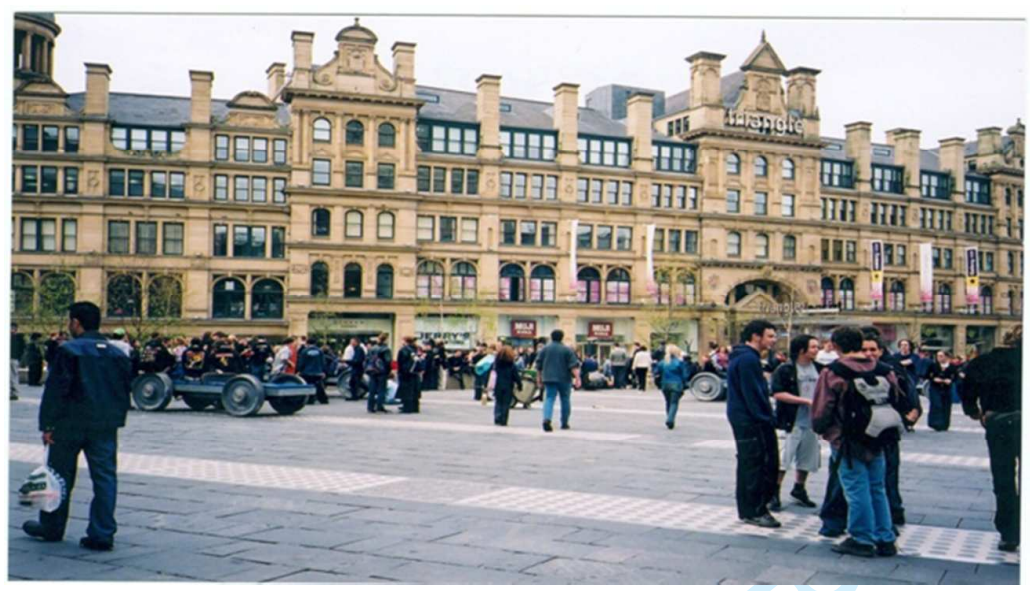

Image 2: Exchange Square

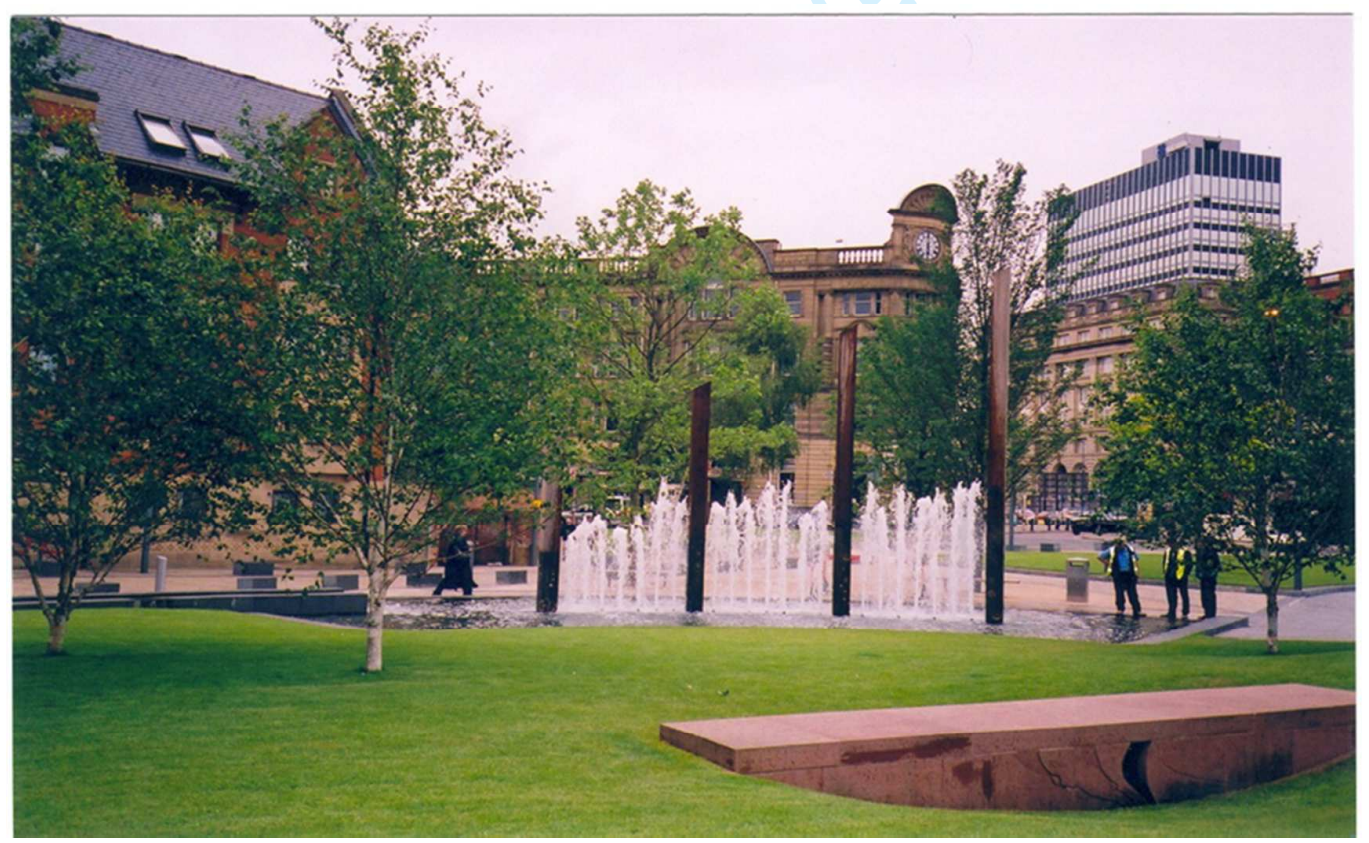

Image 3: Cathedral Gardens 


\section{Introduction}

Using observational data from two spaces of consumption in Manchester city centre, this article aims to use Lefebvre's (2010) rhythmanalysis, to identify examples of arrhythmia, eurhythmia and polyrhthmia, during periods of ordinary and extraordinary use. "The extra-ordinary [...] offers a key hook for understanding the production of knowingly different places and practices" (Kraftl 2009: 128). The key question is: how do the rhythms of teenage life differ when ordinary and extraordinary activities occur in sites of consumption? A contribution is made to existing research on young peoples' behaviour in urban public space (Atkinson 2003; Beneker et al 2010; Massey 2007 and 2008; Malone 2002; Matthews et al 2000a; Matthews et al 2000b; Skelton 2000; Pain 2001; Valentine and Skelton 1998) using participant observation methodology. With the exception of Kullman and Palludar (2011) rhythmanalysis has not been used to examine young peoples' use of urban public space. Edensor and Hollloway (2008) note Lefebvre's rhythmanalysis lacks extensive use as a means of investigating urban space. This is unfortunate as it allows an investigation of not only who is present, but when and for how long they engage in activities there, thus revealing the truly temporal and dynamic nature of urban space. However, Edensor's (2010) work does give numerous accounts using rhythmanalysis as a theoretical framework.

The observation and study of urban public space allows an understanding of more than peoples' behaviour, routines and rhythms. It also reveals much about the cultural practices of place and existing hierarchies of power (Low 2000). These hierarchies are linked to capitalism and consumption. "Our cities are what and where we consume. In essence, the city is in fact nothing more than a space for consumption in which we apparently express ourselves as citizens of a consumer society" (Miles 2010: 1). The impact of consumption on urban space should not be underestimated as arguably "the result is a subtle privatisation of public space as commercial imperatives define acceptable behaviour, excluding those who detract from the consumption experience" (Fyfe and Bannister 1998: 263). The examination of urban space is meaningful because we cannot exist without space and as individuals, we create meaningful spaces (Stephen 2003). In addition "a spatial analysis - particularly one recognizing the social production of space, as in Lefebvre (1991) - recognizes the inherent and multiple social meanings of space and the spatiality of all human activity" (Martin et al 2003:114). Whilst urban space is important, the rhythm of human life also warrants investigation as "our lives and the spaces we dwell in and move through are composed of a multitude of different rhythms, temporalities, pacings and measures" (Edensor and Holloway 2008: 483). How can rhythmanalysis contribute to how we think about spaces of consumption? Might it create an alternative view?

\section{Lefebvre and Urban Space}

Lefebvre (1991) argues from a Marxist perspective that capital and capitalism affect all practical matters regarding space. "The commodity prevails over everything" (Lefebvre 2010:6). There are three fields of space: physical, mental and social; all 
three must be present for the production of space as physical space only becomes real once energy unfolds within it (Lefebvre 1991). Mitchell (2003) concurs "public space is thus socially produced though its use as a public space" (Mitchell 2003: 129). Lefebvre asserts as public space becomes more controlled it becomes more prohibiting and enclosed. In summary, for Lefebvre (1991) the influence of capital cannot be ignored and space is complex. As cities are sites of consumption and exist to create profit the role of capital is key. Space is arguably a political tool in capitalist society, used instrumentally as a commodity (Savage, Ward and Warde 2003). A dialectic relationship (creating unity from its opposed parts) exists between what is perceived, conceived and lived in space (Lefebvre 1991). Massey (2005) also agrees space is constituted through interactions and has a relational approach, highlighting the dialectical nature of space.

Unlike de Certeau (1984) who emphasises the importance of the pedestrian above the planner, Lefebvre (1991) opines representations of space (the planner's vision) do have a substantial role and influence in the production of space, with users passively experiencing this imposed representation. Donald's (1992) interpretation of the city as text, understood and read by users is useful, but Lefebvre contends this as space can be read but not in the same way as text on a page, due to over inscription: "thus space indeed 'speaks' - but it does not tell all. Above all it prohibits" (Lefebvre 1991: 42). Lefebvre has faced criticism (Soja 1980, Harvey 2009) as he neglects factors such as roles of production, social (rather than spatial) relations of production and industrial (rather than finance) capital. Indeed, Soja (1989) labels Lefebvre a 'social separatist' who succumbs to a 'fetishism of space'.

Rhythmanalysis explained

Essentially rhythmanalysis is concerned with the minutiae of everyday life, the mundane, quotidian and the causes of things or metaphysics (the underlying nature of things beyond the physical). According to Merrifield (2006) even the most mundane parts of life can be as significant as official histories. Thus, much is learned by studying mundane events, behaviours and actors in public space. Arguably being so commonplace in cities, consumption is a mundane activity in this context. A study of everyday activity can be very revealing as "the everyday is simultaneously the site of theatre for, and what is at stake in a conflict between great indestructible rhythms and the processes imposed by the socio-economic organisation of production, consumption, circulation and habit" (Lefebvre 2010: 73). The temporal nature of urban space allows for multiple rhythms, though some of these are more obvious such as traffic control, shops trading hours and children going to and from school (Cronin 2006) This study aims to look at the everyday rhythms of life to identify how the organisation of production and consumption impact on urban space during periods of ordinary (everyday) and extraordinary (unusual) use.

Lefebvre (2010) focuses on the rhythms, repetitions and patterns of everyday life happening in space. Importantly, habit and routine are not tools of dehumanization or homogenization for Lefebvre, rather they are part of our selfhood. Gardiner (2004) suggests contrasting everyday, seemingly mindless routines with exceptional events 
is not about creating some sort of utopia. Whilst this argument illustrates the fruitfulness of analysing everyday behaviour (including consumption which is an everyday occurrence in cities) on its own merits, for the purpose of this paper it is beneficial to use extraordinary (though by no means utopian or idealist) events in urban public space as a comparative tool for analysis. The duration of events is not of interest to Lefebvre (2010) rather he is concerned with instants, or moments, as he has a cyclical rather than linear view of time. Therefore, it is not about how long something lasts, but particular 'lived' moments creating melody, possibly harmony but essentially a rhythm of everyday life. Theoretically a rhythmanalyst can listen to anything from a house to a street in the same way they could listen to a piece of music (Lefebvre 1992). Any city has rhythms; rush hour in the morning, a lunchtime break, an evening rush hour and finally revellers spend their leisure time there after dark. Latham and McCormack understand "the material as processually emergent" (2004: 701) meaning the city is discursive and somewhat chaotic due to a constant state of flux. The rhythms of cities comprise of consumption (leisure), production (work) and residence (home) by their populations, but cities are also sites of resistance whether this is something minor such as skateboarding or major such as political protest or riot. Essentially the urban is a product of multiple miniscule interactions which are not ordained by any fundamental regulator or decision-making unit (Latham and McCormack 2004). There are of course mechanisms to attempt to control cities whether by capitalism or crime regulation using surveillance such as CCTV (Coleman 2004). With regard to consumption and retail, CCTV is installed in most stores to prevent and detect theft of goods. However, excessive pluralities due to a multitude of users mean overall control or cohesiveness of urban space is a challenging prospect.

Bachelard (1994) argues space is not really experienced as cohesive but more fragmented and this notion is evident in Lefebvre's rhythmanalysis; duration is never unitary and individuals often use the same space for different activities, or interpret space differently. Think of the skateboarder (Borden 2001) who sees a bench as somewhere to perform a new trick rather than eat lunch. Rhythm is implicit in every activity: "everywhere where there is interaction between a place, a time and an expenditure of energy, there is rhythm" (Lefebvre 2010:15). There is a tendency to see rhythm as something mechanical or 'machinic' (Latham and McCormack 2004). For example, in music rhythm is reduced to a number of beats, however, repetitions may be important but no two are identical (Lefebvre 2010). Rhythms are never selfcontained or closed totalities, but rather open occurrences, prone to internal or external changes, shifts and realignments (Gardiner 2004).

Lefebvre identifies three types of rhythm; polyrhythmia. eurhythmia and arryhtmia (2010). Polyrhythmia refers to multiple rhythms occurring simultaneously such as the heart beating and lungs breathing in air. Eurhythmia refers to rhythms uniting to create harmony. Finally, arrhythmia is understood as discordant or mismatched rhythms resulting in an unusual event; the medical term for disturbed rhythm of the heart is arrhythmia. Arrythmia is not necessarily a negative occurrence; a disruption of rhythm may create the conditions for a pleasant unusual event. Kullman and 
Palludan (2011) conducted and ethnographic rhythmanalysis of schoolchildren's journeys and give the example of snow falling as arrhythmia.

According to Lefebvre (2010) there are two ways to study rhythms; firstly the rhythms of the body and secondly as a more arbitrary or subjective phenomena. This article is concerned with the latter rather than biological phenomena, though it is acknowledged without our physical bodies little action could take place in urban space. Undoubtedly, our actions are embodied but the focus here is not on bodily functions or rhythms such as eating, sleeping or excreting waste. It is rhythms created within urban space (occupied by the body) rather than the body itself, which is central to investigation here. There is a distinction between rhythm and movement; rhythm is not like machinery performing a series or sequence of movements. We only know if something is fast or slow in comparison to another rhythm, though this is not as rudimentary as the amount of time something takes, as for Lefebvre the notion of time measured by a clock is too limited and reductionist (2010). Lefebvre is concerned with how time and space create energy and in rhythmanalysis how melody and harmony converge to produce rhythm. An important question here is what can the rhythms created by actors in space tell us about spaces of consumption? Are there rhythms of consumption evident in urban space?

Why Manchester?

Manchester was chosen as a research site not only because of its proximity as the hometown of the researcher, but also because it offered a newly regenerated space, planned and designed to attract the affluent consumer and private investors in order to generate capital. On Saturday 15 June 1996, central Manchester suffered immense physical, social and economic damage when a 3,300lb IRA (Irish Republican Army) bomb exploded in the city. This resulted in the loss of around 49,000 square meters of prime retail space. Prior to bombing the affected area of Manchester was separate from the main retail core, as a busy dual carriageway ran through it. Thus, traffic into the busy central Arndale bus station dictated the rhythm and sense of speed (Latham and McCormack 2004, 2008) of this part of the city. The pedestrian route to the area now known as the Millennium Quarter involved negotiating many stairs and walking through a covered bridge from Shambles Square (an area popular with homeless populations and street drinkers). There was little effort to encourage consumers and the main users of the area were teenagers. The attraction for them was the Corn Exchange building home to numerous stalls selling everything from bootleg goods to second hand records and crystals (Massey 2008). Prior to regeneration land values were comparatively low as the space was less desirable. The rebuilding process ensured the affected part of the city was designed for consumption, by incorporating pedestrian walkways and shops to attract what Miles (2010) terms the 'idealised consumer', who has plenty of disposable income, in stark contrast to the teenagers previously attracted to the area.

\section{INSERT FIG ONE HERE}

Following the bombing, Manchester City Council launched an International Urban Design Competition to facilitate a planning response, accompanied by the 
establishment of a Task Force - Manchester Millennium Limited (MML) including various private sector businesses (Robson 2002). EDAW construction won the competition as they showed the most potential for enhancing the quality and potential for investment into the area, rather than merely redistributing previously existing activity (Williams 2000). Manchester City Council viewed the devastation of the central retail core as an opportunity to radically change and remodel the heart of the city. Inward investment from the private sector helped achieve this goal. The funding infrastructure consisted of an injection of public funds ( $£ 83$ million) which in turn attracted $£ 380$ million of private sector investment. The public sector contribution reduced the risk for private investors who viewed the area as a relatively safe bet due to significant public investment (Hackworth and Smith 2001). Undoubtedly consumption and in particular a certain type of affluent consumer was important for the future if the area, as existing traders in the Corn Exchange were displaced due to increased rents and replaced by upmarket retailers and boutiques. Despite the planners' attempts to subtly 'design out' (Atkinson 2003) non-affluent consumers (such as teenagers) the area continued to attract a large youth population. The youngsters in question belonged to alternative subcultures (known as moshers and emos) who co-existed alongside a handful of skateboarders. Moshers are young people interested in alternative music who wear what they want to rather than what fashion dictates and emos are young people listening to softcore punk music and wearing skinny jeans and woolly jumpers. They gathered in quite large numbers at weekends and during school holidays in Cathedral Gardens, as they often experienced bullying at school (Massey 2008) due to their appearance and only felt a sense of belonging amongst those from similar neo-tribes (Maffesoli 2000).

\section{Gateways for Consumption: Exchange Square and Cathedral Gardens}

Exchange Square is a pedestrianised public space linking the modern shopping core of Manchester with the historic heart of the city. In terms of representations of space (Lefebvre 1991) the planners' notion of order has been inscribed onto the space by designing it for pedestrian activity and primarily as a gateway for consumption; the influence of capital cannot be ignored in this space (Lefebvre 1991, 2010). As illustrated below (fig. 2) Essentially the square facilitates consumption allowing shoppers ease of access from one retail outlet to another. Manchester City Council oil the wheels of consumption during busy times of the year (such as Christmas) encouraging consumers to spend more time and money there by including a Ferris wheel, Christmas market traders and street food stalls in Exchange Square.

Exchange Square is constructed on a number of levels, with the plaza on Corporation Street being at a considerably higher level than the linear fountain. The ramps house a series of very low walls intended as seating, though this architecture is interpreted rather differently by young Mancunian skateboarders. Clearly, we can see de Certeau (1984) was right about pedestrians (or in this case skateboarders) giving shape to space. The planners' response of incorporating curved bars on the walls to prevent skateboarding illustrates order being created via representations of space and the prohibitive quality of space (Lefebvre 1991). In addition to the curved metal bars The introduction of curved metal bars on top of the low walls has 
prevented this. a local byelaw (carrying a fine of $£ 150$ ) also prohibits skateboarding and rollerblading. Despite these measures Sskateboarding continues is as an act of resistance. There are two ways this constitutes an act of resistance; 1) it contravenes a local byelaw and 2) skateboarding does not comply with the-against the-intended vision of purpose of Exchange Square as a site for, which is primarily a site of retail and capital generation. Whilst the practice of skateboarding is not directly transforming or challenging the existing capitalist hegemony, skaters (in general, not just in Exchange Square) are resisting the commodification of their skills as they do not see their activity as a way to make a living but rather as 'a way of living' (Beal 1995). onsumption. The presence of skateboarders may also deter 'legitimate' consumers (Mitchell 2003) who do not wish to negotiate skaters as part of their shopping experience. Glearly, we can see de Centeau (1984) was right about pedestrians (or in this case skateboarders) giving shape to space. The planners' response of incorporating bars to preventskateboarding illustrates-order being ereated via representations of space and the prohibitive quality of space (Lefebve 1991).

\section{INSERT FIG 2 HERE}

\section{Cathedral Gardens}

The gardens comprise of a series of lawns, trees water features, artworks and hard landscape areas, which due to pedestrianisation provide a relatively tranquil area in the city centre. The podium lawns are stepped in places and curved, or rolling in others as a series of pillow lawns to prevent activities such as playing football. Particular attention has been paid to disabled access ensuring all lawns allow disabled access and different coloured hard materials have been used to aid the visually impaired. Whilst capital does have a major impact on city planning (Lefebvre 1991) here, we can see issues such as accessibility and inclusivity as important concerns for planners.

\section{INSERT FIG 3 HERE}

Whilst this space is more heavily used post-bomb regeneration, there are still a number of prohibited behaviours, notably the presence of large groups of youths, which created a dialectics of space (Lefebvre 1991, 2010). The planners did not envisage large groups of teenagers congregating in the area, nor did retailers welcome their presence (Massey 2008). The gardens are an area where young people felt safe (due to being in a busy urban area) yet liberated (as they were free from the prying eyes of parents). Public spaces such as the street "become places which are identified as safe space, affording what Soja (1996) has termed 'thirdspace', where young people gather to affirm their sense of difference and celebrate their feelings of belonging. In essence, these places are 'won out' from the fabric of adult society but are always in constant threat of being reclaimed" (Matthews et al 2000a: 64). In the case of Cathedral Gardens the threat of reclamation was realised, when retailers approached the local police to request the enforcement of a dispersal order in the city centre (Massey 2011). Whilst this was never effectuated, it does illustrate a level of hostility towards teenagers by local retailers, who maybe saw teenagers as interfering with rhythms of consumption. 
Similar to Exchange Square, the space of Cathedral Gardens encourages consumption during the festive season, hosting an ice rink and funfair at Christmas.

\section{Urban Space and Consumption}

Whilst consumption is connected to capital, a direct relationship with wealth is not always necessary as consumption "also includes consumption of gifts, of selfproduced objects, of ready given services, and so on" (Lury 2011: 12). Arguably urban public space is a given service accessible to all, so although they may be created for the purchase of goods "places themselves are in a sense consumed" (Urry 1995:1). The practice of spending time is just as important as spending money (Shove 2009) and where we choose to spend our time is meaningful, as this contributes to identity creation (Lury 2011 Therefore, it is possible to consume or use the city without spending money.

Instead of asking how and why people are using urban space, questions such as how long and when are also pertinent when considering consumption. An investigation of moments can reveal the temporal nature of cities depending on the users and time of day or week. This is something commerce is aware of as Cronin's 2006 study of the way advertisers tailor electronic billboards to the needs of their audience, who may be commuters, parents on the school run or hedonists seeking nightlife. In addition, how consumers interpret or read urban space is key to this study, as the teenagers belonging to subcultures who are the focus of this study, tend to see spaces of consumption as places to meet, socialise with other members of their neo-tribe (Maffesoli 2000) and have a sense of belonging. Undoubtedly, their presence brings a certain 'puissance' or energy to the area (Maffesoli 2000) which is somewhat at odds with the planners' vision of the area as a site for affluent consumers.

\section{Methods}

In total eighty-four observations were undertaken over a period of eighteen months in four different areas of the Millennium Quarter in Manchester City Centre. These four areas included two public spaces (the Millennium Quarter and Exchange Square) and two private spaces (the Printworks leisure complex and the Triangle shopping centre). Data was gathered on each day of the week at three times of day (morning, lunchtime and afternoon) in order to identify distinct uses and rhythms within each space. All four sites are spaces of consumption but for the purposes of this study, only those in public spaces (a total of forty-two observations) were utilised. From these a selection of four illustrate 'typical' and 'extraordinary' use to allow a comparison. There are three reasons for this; firstly, public space is more accessible due to few conditions of entry (Low 2002) and more heavily populated by youths. Secondly, public spaces offer more potential for the observation of extraordinary events as they are used to stage public events. Finally, there are restraints to the amount of data it is possible to analyse in depth within the limits of this article.

The data was gathered from a pedestrian view (de Certeau 1984) whilst sitting on benches, walls and lawns in Exchange Square and Cathedral Gardens. This method 
allows captured moments, as importantly "moments are themselves partial totalities that reflect and refract larger wholes; they constitute a crucial point of linkage between the immediacy and particularity that inheres in the fine grain of everyday life and the broader sweep of sociohistorical change" (Gardiner 2004: 243). Making notes in situ in a small, discreet notebook minimised disturbance of the setting.

Much has been written about the rebuilding process. Massey (2005) argues a gentrification of consumption occurred in the area affected by the bomb. Some theorists (Quilley 2000, Peck and Tickell 1995 and 1999, Peck and Ward 2002, Robson 1994, Williams 2000) imply social exclusion has been a consequence of the remodelling of Manchester. Authors such as Peck and Tickell (1999) express this in terms of corporatist elitism in 'top down' studies. This study aims to illuminate patterns of consumption by observing what is actually happening there, rather than interviewing those connected to the setting. Observation is a more fruitful method for this purpose. In addition, "participant observation continues to produce some of the most interesting and evocative accounts of subculture" (Hebdige 1987: 75) and this method allows an alternative 'bottom up' approach, drawing on the activity of everyday users rather than those in power. The data analysed for Exchange Square draws on observations conducted on Monday lunchtimes and on Sunday afternoons for Cathedral Gardens.

On discovering Lefebvre's (2010) rhythmanalysis after gathering observational data, it seemed an interesting framework for analysis of existing data, which offered evidence of 'lived' moments and illustrated every day and exceptional activity in urban space. Whilst the original intention when data gathering was not to look for rhythms, this is not wholly problematic as the descriptive nature of field notes allowed extrapolation of relevant data. Instances of melody, harmony, arbitrary rhythms, polyrhythmia, eurhythmia and arrhythmia were easily identifiable and carefully selected from the existing forty-two observations. An initial broad-brush analysis identified general rhythms of use or consumption, such as weekly and daily patterns of use. These changed dependent on the time of day or week and identified rhythms similar to those discussed by Cronin (2006). Inspired by Lees (2001) method of presenting data, four vignettes illustrate every day and extraordinary use of both gateways to consumption.

\section{Data Analysis: Exchange Square and Cathedral Gardens}

A broad-brush analysis indicated both Exchange Square and Cathedral Gardens have similar patterns of use. They were both quiet towards the beginning of the week (Monday to Wednesday) and busier later in the week (Thursday and Friday). The busiest period of use was the weekend. Here we can see the social rhythm of the area (Lefebvre 2010) peaks on a Saturday and falls on a Monday. The weather plays a significant role, with heavier use during summer. Both spaces also tend to be used more heavily during school holidays, due to their popularity with teenagers and families. The lunchtime period (between 12 p.m. and 2 p.m.) on weekdays was also busy, with workers from nearby offices taking their break in both spaces. These rhythms are mechanistic and related to capitalist production, which overrides our 
natural circadian rhythms (Elden 2004). We will now turn to data illustrating typical (ordinary) and discriminate (extraordinary) use. It is important to note the data does not claim to give an account of 'typical' use, as this would be difficult to quantify or define, however, observations did highlight dominant groups who had a presence in the area.

\section{Exchange Square}

\section{Vignette 1: ordinary everyday use}

The level of activity is a little higher than usual on this Monday lunchtime due to local school holidays. It is a cold day in February, but the sun is shining making it a bright but chilly day. There are a group of eight teenagers sat on one of the low walls, six of them move off leaving two on the wall. Another teenage male joins them and the group now has three male teenagers. Two of them sit on the wall and the other stands. He wears a short- sleeved white shirt with a long sleeved black T-shirt underneath and a school tie around the neck of the shirt. He leaves the group and ten minutes pass as the two other boys sit on the wall. They chat to two other teenagers who they were not with earlier, though the other two teenagers have been in the square for the same amount of time. It is difficult to tell whether they know each other or have just met, but it seems that they only know each other vaguely as there is quite a large amount of distance between the two pairs of teenagers. They are certainly not as close as the groups of eight and three teenagers described earlier. A few minutes pass and then three teenagers, all male, wearing skating clothes come and sit on the wall opposite. Two more boys come and join them making a group of five. They shout out to two teenage girls who are exiting a nearby building: "Hello, are you deaf as well as blind?" and the girls come over. They know each other as one of the boys introduces the girls to his friends using their first names. One of the girls has a Homer Simpson rucksack on her back. Both girls are dressed casually wearing black hooded tops and jeans. The girls stay chatting with the boys for five or ten minutes and then they walk off. The teenage boys sit chatting for another couple of minutes; they start moving around on the wall and using a skateboard one of them has with them. About five minutes later three teenage girls (including one from earlier with a Homer Simpson rucksack) return to the group. She shows her friends something she has just bought; it looks like a small figurine. The group is now four males and three female teenagers. They all seem to know each other well and they are happy to chat and compare socks, as one of them announces, "I've got new socks" and pulls up their trousers to reveal red and black striped socks. Others in the group reveal their striped socks, which are red and white, black and white or red and black.

\section{Vignette1: findings}

Undoubtedly at weekends, Exchange Square is a popular meeting place for teenagers, who gather there to watch their peers skateboarding. Such activity is arrhythmic (Lefebvre 2010) as it is breaking a local byelaw which prohibits rollerblading and skating. An interesting characteristic of groups of teenagers is they tend to have quite fluid membership of groups. They mix with those from other groups quite freely and though they had relatively, clearly observable groups were 
happy to include others belonging to what Maffesoli (2000) would call 'neo-tribes'. Another striking factor when observing teenagers is they are not only identifiable by their youthful appearance but also by their clothing. They all wore hooded tops and baggy jeans and in some cases brightly coloured socks. Arguably, such clothing choices denote membership of a certain group, or commitment to a subculture the teenagers engage in, as an expression of identity and an escape from the monotony of school and home (Hebdige 1978). The teenagers can be read (Donald 1992) as part of the city both by other teenagers and the public generally. There are obvious messages conveyed by items such as T-shirts with the names of bands on them, which indicate personal tastes to other teenagers. However, there are more subtle symbols at play here, such as stripy socks. The display of socks to each other (initially hidden beneath their jeans) illustrate a common bond with each other. This behaviour is eurhythmic as it indicates harmony and similarity amongst these individuals (Lefebvre 2010). Consumption (buying a particular type clothing) facilitates this behaviour. Having said this it is unlikely, the teenagers in question would see themselves as wholly eurhythmic. These young people tend to perceive themselves as individuals and earlier research (Massey 2008) indicated they detest being categorized or labelled as belonging to a particular group.

\section{Vignette 2: extraordinary extra-everyday use}

On a sunny humid Monday afternoon during an international sporting event, Exchange Square is crowded. Numerous events are taking place; the main attraction is a percussion band playing to the crowd as a litter collector passes by. The water feature is churning clear cool water from its enormous taps and a little three or fouryear old girl in a pram is screaming. She wants to go back and play in the water feature, but her mum will not allow this as the little girl's dress is wet. The child is strapped into her buggy in her underwear by her mum. Her grandma is also with them and the mother and grandmother start chatting to a man in his thirties who is wearing sunglasses. They are talking about how important it is that the little girl learns not to get her clothes wet. The man does not appear to know the two women and they all seem to be chatting partly because they are in such close proximity to each other and partly because the mother wants to relieve some of her embarrassment at her daughters' screaming, by explaining to the young man why she won't allow her to get wet. Numerous groups of people sit on the walls enjoying the sunshine and percussion band. There are many different age groups here, from young toddlers with their parents, to teenagers, to adults and people in their fifties and sixties. The soundscape of the square is quite different today. The percussion band and applause of the crowd drown out the sound of the traffic.

Vignette 2: Findings

The discriminate or 'arrhythmic' example of Exchange Square reveals a number of findings. During times of festival social links are loosened as "festivals were like everyday life, only more intense, more graphic, more raw. During festivals, people dropped their veils and stopped performing" (Merrifield 2006: 14). The data showed the mother of a child was happy to engage in conversation with a complete stranger at this time, though this did not happen during any of the other observations. What 
was it about the conditions on that day that encouraged interaction? There are a number of possible answers. The most obvious one is the festival atmosphere in the square led to this interaction. Another is that the mother's embarrassment by her daughters' screaming, resulting in an explanation to a complete stranger. Such interaction between a man and a woman is unusual in urban space during the day, as the majority of other data gathered indicated women in public space tend to keep themselves busy to avoid interaction with strangers, especially the opposite sex (Gardner 1990). Lone women are usually engaged in some sort of activity such as reading, eating or chatting on the phone. However, this woman was not alone; she had her child and her mother with her. This reduces the amount of 'stranger danger' (Ahmed 2000) posed by a male stranger. This finding is gender-specific, an area Lefebvre often neglects according to his critics (Blum and Nast 1996, Felski cited in Gardiner 2004). We can conclude here that during periods of arrhythmia, when space usage is distinct from its everyday use, unusual or non-typical behaviour takes place, supporting Merrifield's (2006) argument that people drop their veils and stop performing.

The role of consumption and capital is interesting here as consumption is occurring but this is more experiential (Shove 2009) than financial, as people are spending time (listening to live music) rather than capital. The retail outlets are obviously still open and people are free to shop there, but events such as live musical performances have fewer restrictions in comparison to a fun fair or Ferris wheel (which have an entrance fee) meaning space is less commodified. With reference to teenagers, it is interesting to note they do not have a dominant presence during extraordinary events observed here. They are not strictly speaking absent but have been outnumbered or possibly displaced by events in Exchange Square. It is of course possible the teenagers are engaged in acts of consumption elsewhere in the city. However, given their typically limited disposable income, this seems unlikely and it is more probable the presence of large crowds and a percussion band create arrhythmia for the teenagers typically associated with this space.

\section{Cathedral Gardens}

\section{Vignette 3: ordinary everyday use}

On a sunny Sunday afternoon in early September Cathedral Gardens is quite busy with lots of people sat around on the lawns and walls. A couple of skaters come through the centre of the park on skateboards, one climbs up all four of the steps laid into the grass. He is a teenager, with a bright red skinhead haircut. He goes with his friend to the area in front of the cathedral where the paving is particularly smooth. A group of moshers are near Urbis, they are all giving each other high fives. The group is made up of what looks like (though it is difficult to tell due to their unisex clothing and hairstyles) six girls and five boys. They all go and sit down on the grass near the sandstone walls. There are three skaters now as another male teenager joins the existing group and they all discuss tactics as they try to skate on the wall. One says 'why do you think you can make the end?' and then 'hard isn't it' after one of them unsuccessfully attempts it. A police motorbike goes past in front of the building opposite and they all freeze waiting for him to pass. The teenager with the red hair 
and the other with the grey T-shirt seem to be doing all the skating while the other just stands watching. One of them says 'here the security guard's coming' but they carry on regardless. They are getting better and better at jumping the wall as they practice; now the one in the grey T-Shirt is skating along wall towards Starbucks. They are getting closer to the main street now and all three of them move off towards Exchange Square.

Vignette 3: Findings

Whilst Cathedral Gardens serves a number of purposes (a place to meet, for children to play, to sit and take a break or engage in consumption) and people of all ages, ethnicities and genders frequent it, the dominant users of the area throughout the year are large groups of teenagers. The attraction for the moshers seemed to be purely as a meeting place, somewhere that was easily accessible via public transport and a place to hang out away from the prying eyes of their parents. Surveillance raises an interesting paradox here, as the teenagers are not under parental surveillance, however, the long arm of the law was present, albeit in the background. The skateboarders are attracted to the area literally by design. Cathedral Gardens offers a series of very smooth surfaces and low steps/walls perfect for skateboarding. In this sense the space is what Flusty would describe as 'prime 'crete' (2000: 154). The way the skaters respond to the passing police motorbike (they freeze) is evidence of their knowledge of engaging in prohibited behaviour (skateboarding). In one sense, this is an example of arrhythmia as a police presence constitutes a discordant rhythm for the teenagers who are skateboarding. The sight of the officer on a motorbike interrupts their skateboarding rhythm. However, others may view the police as ensuring eurhythmia as their role is to keep the peace and ensure harmony. Arguably, this illustrates multiple understandings of the same event (the police officer being present) as whether behaviour is harmonious or discordant is a subjective issue. It is also evidence of multiple rhythms being present, contributing to the complexity of the plural production of urban public space.

Although the skateboarders were engaged in acts of resistance breaking a local byelaw, the groups of moshers and emos were not doing anything illegal by hanging out with their friends. It is not necessarily their activities in Cathedral Gardens that cause concern but rather the sheer numbers gathering there. This sometimes attracts attention from the authorities. The moshers did not correspond with the image or 'aesthetics of authority' (Ferrell 1995) of a newly regenerated and gentrified urban area. Similarly Zukin (1995) uses the term 'aesthetics of fear' to refer to groups who may somehow pose a threat in spaces of consumption. Historically, teenagers have always hung out with their friends and engaged in boisterous and slightly rebellious behaviour. This does not always involve consumption in a conventional sense. In fact teenagers tend to have a reduced 'right to the city' (Mitchell 2003) as they tend to repel rather than attract 'legitimate' consumers. Important questions here are how did they come to dominate this space? Do they have any real power in this space? How has it become their place? Was there a contest for this space? Dialectics are important here and ultimately there was a contest for this space and agreement eventually reached via a Peer Youth Worker Scheme (Massey 2008). 


\section{Vignette 4: extraordinary extra-everyday use}

On a glorious day in July, a warm breeze accompanies bright sunshine and Cathedral Gardens is a hive of activity. There is a fifteen-foot tall inflatable figure bobbing about in the breeze at the entrance to the gardens. There are five or six white gazebos set up, some of them have TV screens inside and youngsters are watching the screens. Another gazebo has a union jack on the roof and actors perform in this makeshift theatre space. The rear of the park is less busy as this area is relatively untouched, but the noisy whirring of a power generator disturbs the soundscape. A tribal band in costume with instruments are standing in one of the gazebos nearby and look like they will be playing soon. Many people relax on the lawns, some eating lunch and some are workers at the international sporting event the city is hosting (some in uniform some in plain clothes but their huge badges round their necks give them away). A man in a jester's outfit unicycles in the distance. The water feature is running and children are frolicking about in it. A woman in her thirties is sunbathing but she does not look relaxed, she is holding her body quite stiffly, her legs are very straight and her arms by her side. A tanned man with a blond Mohican is lying on the grass near a wall, he looks much more relaxed; he is lay down but has his feet and arms more far apart and is spread out more. A man sits on the wall leaning back, though it is difficult to ascertain his age as his face is not visible. He is holding a mobile phone in his right hand but is not using it and has his coat on the wall to his left; he is just looking around at what is happening. Two young boys aged seven to ten years run through, one has rolled up trousers and wet legs, their mother is with them but lets them run off around the park to do their own thing. The man leaning back on the wall stands up and leaves. A litter collector passes and picks up a stray Coke can and puts it in a blue Manchester City Council litterbag. A police van parks near Victoria Station, a reminder of law and order. Both sunbathers from earlier are sat up now, the woman is drinking water whilst the male sits back on the wall. The soundscape has the water feature in the background though the noise of the generator and children playing in the fountain and screaming almost drowns this out.

Vignette 4: Findings

Here we can see a polyrhythmia of various activities occurring simultaneously. The parked police van is there to restore eurhythmia should any conflict occur. As in vignette 2 people appear to be spending time rather than money (Shove 2009) in the gardens, as most are engaged in sunbathing, listening to live music or enjoying free activities such as playing in the fountain. Interestingly none of the regular users (skaters and moshers) are present in the gardens on this occasion. Arguably, the hosting of an international sports event in the city created an arrhythmia of everyday use for teenagers, despite eurhythmia and polyrhythmia (Lefebvre 2010) being evident. The regular users displaced by official activities organised by Manchester City Council, which attract an alternative (and some may argue more legitimate) user with more 'right to the city' (Mitchell 2003). 
This article has used Lefebvre's (2010) concept of rhythmanalysis to identify examples of arrhythmia, eurhythmia and polyrhthmia, during periods of ordinary and extraordinary use. During periods of ordinary use, teenagers' behaviour was eurhythmic, sharing fashion sense and interests such as music and skateboarding. The skaters represent a resistance threat to capitalism, as not only are the skaters not spending vast amounts of money whilst skating, but also they may discourage consumers who do not want to negotiate skateboarders in the city centre. This is due to the privatisation of public space (Fyfe and Bannister 1998) and remodelling of Manchester to attract the 'ideal consumer (Miles 2010) or 'legitimate' user (Mitchell 2003). Having said this skaters can also bring a dynamism and edginess to the city (Woolley and Johns 2001) and they are consumers themselves as they buy into the identity of 'skater' by purchasing skateboarding equipment and clothing (Lury 2011). Whilst the moshers are an eurhythmic group as there was no animosity between them, the presence of large groups of youngsters is often an unwelcome addition to public space. Pain (2001) argues this is a paradox of youth who are both vulnerable and dangerous. Interestingly large numbers of 'ideal consumers' (Miles 2010) are welcomed rather than viewed as a risk in spaces of consumption when organised events are being staged. This is despite not spending huge amounts of capital when listening to a musical performance. Therefore, it is not only teenagers' limited access to disposable income but also their appearance. Large groups of youths may be perceived as a 'threat' to 'legitimate' rhythms of consumption as they do not conform to the 'aesthetics of authority' (Ferrell 1995).

In terms of how rhythmanalysis contributes to how we think about spaces of consumption it is evident rhythms and consumers do differ dependent on what is happening in the city. Observation of the same space at different times reveals disparate results, indicating it is not just who is present (or absent) but when they are there which is exigent. Rhythmanalysis can aid an understanding of consumption based not only on who the consumer is, but also when they are present and for how long. This contributes to our understanding of urban space as temporal and fluid. Findings may differ significantly dependent on the time of day, week or year, indicating whilst there may be patterns of use they are rarely 'typical'. The plural nature of public space leads to a range of contestations over the meaning of any particular space by its users and planners. During both ordinary and extraordinary use, instances of harmony (eurhythmia) were identified. Arrhythmia and polyrhythmia are evident during mundane use, but not during extraordinary use. There are two possible reasons for this. Firstly, when events organised by the city council occur the purpose of consumption in the area is clearly defined. Stage performances provide a focal point for the crowds gathering there who are engaged in consuming the entertainment on offer, rather than using retailers there. This allows little opportunity for polyrhythmia as the majority of people there are engaged in the unitary activity of listening to a musical performance. Secondly, a high presence of police officers, security personnel and volunteers (employed for the hosting of an international sporting event) lessened the possibility of arrhythmia. Space is more prohibiting when it is more controlled (Lefebvre 2010) and this was especially true for teenagers who were displaced to other parts of the city where maybe they could have more freedom.

Lefebvre argues extra-everyday rhythms do not disturb the everydayness of a space (Lefebvre 2010). At first glance, the data analysed here during extraordinary use 
rejects this hypothesis. The events staged as part of an international sporting event in the city could fit into the category of 'carnival', which "can be seen as an exemplary time when everyday rhythms, like other ordering principles, are suspended" (Edensor 2010: 16). However, whilst those present in the spaces changed dependent on events there, the activities viewed as legitimate such as consumption or not skateboarding did not. Therefore, if capitalist ideology (and consumption) are part of the everydayness of urban space for Lefebvre, this does not change regardless of extraordinary use. Those using the setting may change but it is still a gateway for consumption; the retailers are still open for business.

Nonetheless, rhythmanalysis has revealed the type of consumption changed during extraordinary use, as on both occasions people appeared to be spending time rather than money in Exchange Square and Cathedral Gardens. Arguably, consumption plays a key role in cities and some teenage activities are detrimental to this (Goss 1993) and therefore capitalism. There did not seem to be room for polyrhythmia (for the regular and extraordinary users to occupy this space simultaneously). In short, events observed here interrupted existing teenage rhythms.

\section{Bibliography}

Ahmed S 2000 Strange Encounters: Embodied Others in Post-coloniality London, Routledge

Atkinson R 2003 Domestication by cappuccino or a revenge on urban space? Control and empowerment in the management of public space Urban studies 40 , 1829-1843

\section{Bachelard G 1994 The Poetics of Space Boston, Beacon Press}

\section{Beal B 1995 Disqualifying the Official: An Exploration of Social Resistance through} the Subculture of Skateboarding Sociology of Sport Journal 12 252-267

Beneker, T, Sanders, R, Tani, S and Taylor, L 2010 Picturing the city: young people's representations of urban environments Children's Geographies, 8, 123-140

Blum V and Nast J 1996 Where's the difference? The heterosexualization of alterity in Henri Lefebvre and Jacques Lacan Environment and Planning D: Society and Space, 14, 559-580

Borden I 2001 Skateboarding, Space and the City: Architecture and the Body Oxford, Berg

\section{Certeau M de 1984 The Practice of Everyday life London, Berkeley}

Coleman, R (2004) Reclaiming the Streets: Surveillance, Social Control and the City, Devon: Willan

Cronin, A, M (2006) Advertising and the metabolism of the city: urban space, commodity rhythms Environment and Planning D: Society and Space volume 24, 615- 632 
Donald J 1992 Metropolis: the City as Text in Bocock R and Thompson K eds Social and Cultural Forms of Modernity Cambridge, Polity Press

Edensor, T (2010) Introduction: Thinking about rhythm and space in Edensor, T (Ed.) Geographies of Rhythm: Nature, Place, Mobilities and Bodies, Surrey: Ashgate

Edensor T and Holloway $\mathrm{J} 2008$ Rhythmanalysing the coach tour: the Ring of Kerry, Ireland Transactions; Institute of British Geographers: 33, 483-501

Elden, S (2004) Understanding Henri Lefebvre: Theory and the possible, London: Continuum

Ferrell J 1995 Culture, Crime and Cultural Criminology Journal of Criminal Justice and Popular Culture, 3, 45-42

Flusty S 2000 Thrashing Downtown: Play as Resistance to the Spatial and Representational Regulation of Los Angeles in Cities 17, 149-158

Fyfe N and Bannister J 1998 The Eyes Upon the Street: Closed Circuit Television Surveillance and the City in Fyfe $\mathrm{N}$ and Bannister $\mathrm{J}$ eds Images of the Street:

Planning,Identity and Control in Public Space London, Routledge

Gardiner M 2004 Everyday utopianism: Lefebvre and his critics Cultural Studies, 18, 228- 254

Gardner C B 1990 Safe Conduct: Women, Crime, and Safe Public Places Social Problems 37, 311-328

Goss, J (1993) The "Magic of the Mall": An Analysis of Form, Function, and Meaning in the Contemporary Retail Built Environment, Annals of the Association of American Geographers, Vol. 83, No. 1 (Mar., 1993), pp. 18-47

Hackworth J and Smith N 2001 The Changing State of Gentrification, Tijdschrift voor Economische en Sociale Geographie, 92, 161-177

Harvey, D (2009) Social Justice and the City: Geographies of Justice and Social Transformation, USA: University of Georgia Press

Hebdige, D (1987) Subculture: The Meaning of Style, London: Methuen

Kraftl P 2009 Living in an artwork: the extraordinary geographies of the Hundertwasser-Haus, 1 Vienna Cultural Geographies, 16, 111-134

Kullman K and Palludan C 2011 Rhythmanalytical sketches: agencies, school journeys, temporalities in Children's Geographies, 9, 347-359

Latham A and McCormack D P 2004 Moving cities: rethinking the materialities of urban geographies in progress Human geography 28, 701-724 
Latham A and McCormack D P 2008 Speed and Slowness in Hall T Hubbard P and Rennie Short J eds The Sage Companion to the City London, Sage

Lees L 2001 Towards a critical geography of architecture: the case of an ersatz colosseum Ecumene 8, 51-86

Lefebvre H 1991 The Production of Space Oxford, Blackwell

Lefebvre H 1992 Elements de Rythmanalyse: Introduction a la Connissance des Rythmes, Paris, Editions Syllepse

Lefebvre H 2010 Rhythmanalysis: Space, Time and Everyday Life London, Continuum International Publishing Group

Low S 2000 On the Plaza: the Politics of Public Space and Culture USA, University of Texas Press

Low S 2002 Spaces of Reflection, Recovery and Resistance: Reimagining the Postindustrial Plaza in Sorkin M and Zukin S eds After the World Trade Center: Rethinking New York City New York, Routledge

Lury, C (2011) Consumer Culture (2e), Cambridge: Polity Press

Maffesoli, M (2000) The Time of the Tribes: The Decline of Individualism in Mass Society, London: Sage

Malone K 2002 Street life: youth, culture and competing uses of public space Environment and Urbanization 14, 157-168

Manchester City Council 2002 Manchester City Centre Strategic plan 2002-2005: Draft for Consultation Manchester, Manchester City Centre Management Company Ltd

Manchester City Council 1998 Millennium Quarter Proposals Manchester, Manchester City Council

Manchester City Council 1997 Manchester Two Thousand: The Changing Face Manchester, Manchester City Council and Manchester Millennium Limited

Manchester Millennium Limited 1997 First Implementation Plan Manchester, MML and MCC Manchester Millennium Limited 2001 Manchester Manchester, Manchester City Council

Martin D McCann E and Purcell M 2003 Space, Scale, Governance, and Representation: Contemporary Geographical Perspectives on Urban Politics and Policy Journal of Urban Affairs 25,113-121

Massey D 2005 For Space London, Sage 
Massey, J 2005 The gentrification of consumption: a view from Manchester, Sociological Research Online, 10, 1-11

Massey, J 2007 Young People and the 'Right' to the City in The International Journal of Diversity in Organisations, Communities and Nations, Vol. 7

Massey J 2008 Young people, policing and urban space: a case study of the Manchester Millennium Quarter Safer Communities, 7, 17-24

Massey J 2011 Commodification, Control and Civic Space: Findings from Manchester, UK Crime Prevention and Community Safety: An International Journal $13,187-284$

Matthews H Limb, M and Taylor, M 2000a The 'Street as Thirdspace' in Holloway S $L$ and Valentine $G$ eds Children's Geographies: Playing, Living, Learning London, Routledge

Matthews H Taylor M Sherwood K Tucker F and Limb M 2000b Growing-up in the countryside: children and the rural idyll Journal of Rural Studies 16,141-153

Merrifield A 2006 Henri Lefebvre: A Critical Introduction London, Routledge

Miles, S (2010) Spaces for Consumption, London: Sage

Mitchell D 2003 The Right to the City: Social Justice and the Fight for Public Space New York, The Guildford Press

Pain R 2001 Gender, Race, Age and Fear in the City Urban Studies, 38, 899-913

Peck J and Tickell A 1995 Business Goes Local: Dissecting the 'Business Agenda' Manchester International Journal of Urban and Regional Research 19, 55-78

Peck J and Tickell A 1999 Rescripting Urban Regeneration, the Mancunian Way in Imrie $\mathrm{R}$ and Thomas $\mathrm{H}$ eds British Urban Policy (2nd Edition) London, Sage

Peck J and Ward K eds 2002 City of Revolution: Restructuring Manchester Manchester, Manchester University Press

Quilley S 2000 Manchester First: From Municipal Socialism to the Entrepreneurial City International Journal of Urban and Regional Research 24, 601-615

Robson B 1994 Assessing the Impact of Urban Policy London, HMSO

Robson B 2002 Mancunian Ways: The Politics of Regeneration in Peck J and Ward K eds City of Revolution: Restructuring Manchester Manchester, Manchester University Press

Savage M Warde A and Ward K 2003 Urban Sociology, Capitalism and Modernity (2nd Edition) Hampshire, Palgrave Macmillan 
Shove, E (2009) Everyday Practice and the Production and Consumption of time in Shove, E, Trentmann, F and Wil, R (Eds.) Time, Consumption and Everyday Life: Practice, Materiality and Culture, Oxford: Berg

Skelton T 2000 Teenage girls and 'public' space in the Rhondda Valleys South Wales in Holloway, S and Valentine, G eds Children's Geographies: Playing, living. Learning London: Routledge

Soja, E 1996 Thirdspace: Journeys to Los Angeles and other real-and-imagined places, Oxford: Wiley-Blackwell

Soja E 1989 Postmodern Geographies: The Reassertion of Space in Critical Social theory London, Verso

Soja, E (2010) The socio-spatial dialectic, Annals of the Association of American Geographers, 70:2, 207-225,

Stephen A 2003 Intrinsic Information in the Making of Public Space: A Case Example of the Museum Space, Space and Culture, 6, 309-329

Urban Alternatives (2009) The Cathedral Gardens Project http://www.urbanalternatives.org.uk/help/CGP4.htm accessed 2009

Urry, J (1995) Consuming Places, London: Routledge

Valentine G and Skelton T (Eds.) 1998 Cool Places: Geographies of Youth Culture London, Routledge

Williams G 2000 Rebuilding the Entrepreneurial City: The Master Planning Response to the Bombing of Manchester City Centre Environment and Planning B: Planning and Design, 27, 485-505

Woolley, H \& Johns, R (2001) Skateboarding: The City as a Playground, Journal of Urban Design, 6:2, 211-230,

Zukin, S (1995) The Culture of Cities, Oxford: Blackwell 